
FciDoc

\title{
Comparison of Arndt-Endobronchial Blocker Set (AEBS) with Double-Lumens Endobronchial Tube (DLT) in One Lung Ventilation in Thoracic Surgery
}

Research Article

Zhang Z, Zheng M, Nie Y, Niu Z*

Department of Anesthesiology, The Cangzhou Central Hospital, Cangzhou, Hebei, PR China.

\section{Abstract}

One lung ventilation (OLV) for thoracic surgery is usually achieved with a double-lumen endobronchial tube (DLT) or bronchial blocker. However, nasal intubation is not easy in some cases. Here, we investigate the comparison between the use of Arndtendobronchial blocker set (AEBS) and DLT in OLV in thoracic surgery.

A prospective, randomized, blinded controlled clinical trial was carried out on forty patients aged 44 to 74 , with ASA I or II who scheduled for elective thoracic surgery. Patients were divided into AEBS and DLT group. Those in the AEBS group were inserted with Arndt-endobronchial blocker set while those in the DLT group were inserted with double-lumens endotracheal tube. Airway pressure, effective rate for lung collapse and surgical field exposure (Campos et al., method), incidence and severity (via numerical rating scale) of throat pain were measured.

$\mathrm{PaO}_{2}$ in patients of the AEBS group was significantly lower than the DLT group $(106 \pm 52$ vs. $155 \pm 46)(\mathrm{P}<0.05)$ with $\mathrm{SaPO}_{2}$ within $97 \%-100 \%$. The effective rate for lung collapse and surgical field exposure in the AEBS group was significantly higher than the DLT group $(20 / 20=100 \%$ vs. $18 / 20=90 \%)(P<0.05)$ while the incidence and severity of throat pain of patients in the AEBS group at 6,12 and $24 \mathrm{~h}$ post-surgery were significantly lower than the DLT group $(\mathrm{P}<0.05)$.

Thus, Arndt-endobronchial blocker can be an effective alternative choice for OLV with effective lung collapse and surgical field exposure and less incidence and severity of throat pain.

Keywords: Arndt-Endobronchial Blocker; AEBS; DLT; One Lung Ventilation; Thoracic Surgery.

Abbreviations: AEBS: Arndt-Endobronchial Blocker; DLT: Double-Lumens Endobronchial Tube; OLV: One Lung Ventilation; FEV1: Forced Expiratory Volume in 1s; FRC: Functional Residual Capacity; RV: Residual Volume; TLC: Total Lung Capacity; Ppeak: Peak Inspiratory Airway Pressure; Pplateau: End-Inspiratory Airway Pressure; PEEPi: Intrinsic Positive End-Expiratory Pressure; $\mathrm{P}(\mathrm{A}-\mathrm{a}) \mathrm{O}_{2}$ : Alveolar-Arterial Oxygen Tension Difference.

\section{Introduction}

One-lung ventilation (OLV) consists of mechanical ventilation of the selected lung and exposure or intentional airway blocking of the other. This technique facilitates viewing of intrathoracic structures, thereby providing optimal surgical conditions, since adequate pulmonary exposure facilitates resection and reduces surgical time $[1,2]$. However, this procedure has been associated with reduced arterial oxygen tension, particularly in patients with previous history of lung disease, as it reduces the surface area available for gas exchange and causes a loss of normal autonomic respiratory regulation $[3]$.

Maintaining sufficient oxygenation and elimination of carbon dioxide is the greatest challenge in the management of OLV. Several alternative methods to minimize hypoxemia during OLV have been proposed, including the correct positioning of the doublelumen tube (DLT), use of positive end-expiratory pressure or continuous positive airway pressure, nitric oxide administration and alveolar recruitment [3].

Management of OLV continues to be a challenge in clinical practice [3]. OLV for thoracic surgical procedures is usually achieved

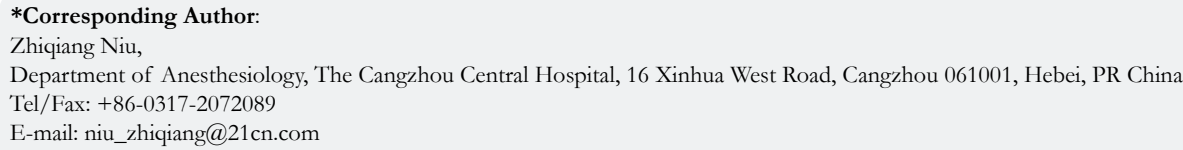

Citation: Zhang Z, Zheng M, Nie Y, Niu Z (2017) Comparison of Arndt-Endobronchial Blocker Set (AEBS) with Double-Lumens Endobronchial Tube (DLT) in One Lung Ventilation in Thoracic Surgery. Int J Anesth Res. 5(4), 429-434. doi: http://dx.doi.org/10.19070/2332-2780-1700088

Copyright: Niu $\mathbf{Z}^{\circ}$ 2017. This is an open-access article distributed under the terms of the Creative Commons Attribution License, which permits unrestricted use, distri bution and reproduction in any medium, provided the original author and source are credited. 
with a double-lumen endobronchial tube (DLT) or a bronchial blocker [4] However, nasal intubation is not easy with a DLT in some cases due to its large outer diameter and the distal curvature [5]. It is difficult to place a DLT in patients with a difficult airway (Mallampati grade view 3 or 4), patients with restricted mouth opening or limited neck extension, etc. as it is bulkier and more rigid than a single-lumen endotracheal tube $[6,7]$. Distortion of the tracheobronchial tree would cause difficulties in placement of a DLT. An Arndt bronchial blocker might be ideal for the provision of OLV.

In our study, we investigate the comparison between the airway pressure, effective rate for lung collapse and surgical field exposure, incidence and severity of throat pain of the patients between the Arndt-endobronchial blocker set (AEBS) and double-lumens endobronchial tube (DLT) in one lung ventilation in thoracic surgery.

\section{Materials and Methods}

\section{Selection of patients}

40 patients with ASA I and II who scheduled for elective thoracic surgery in 2016 were randomly divided into 2 groups, AEBS group and DLT group, with 20 patients in each group. Patients in the AEBS group were inserted with Arndt-endobronchial blocker set (AEBS) (Cook ${ }^{\circledR}$ Critical Care, Bloomington, Indiana, USA) while patients in the DLT group were inserted with double-lumens endotracheal tube (DLT) (Broncho-cathTM, Mallinckrodt Laboratories, Athlone, Ireland). Allocation was performed using sealed envelope system.

Exclusion criteria included age $<20$ years, pre-operative hoarseness, increased risk of aspiration, mouth opening of $<2.5 \mathrm{~cm}$ and surgeries predicted to have long durations.

\section{Methods of anaesthesia}

All patients were premedicated with $0.01 \mathrm{mg} / \mathrm{kg} \mathrm{i} / \mathrm{m}$ injection of penehyclidine hydrochoride and $0.04 \mathrm{mg} / \mathrm{kg}$ of midazolam 30 min before induction of anesthesia. After arrival in the operation room, an $\mathrm{i} / \mathrm{v}$ cannula was placed and patients were given infusion of Ringer's solution at $5 \mathrm{ml} / \mathrm{kg} / \mathrm{hr}$. General anesthesia was induced with 3 - $5 \mu \mathrm{g} / \mathrm{kg}$ fentanyl, 1.5 - $2 \mathrm{mg} / \mathrm{kg}$ propofol and 0.1 - $0.15 \mathrm{mg} / \mathrm{kg}$ vecuronium for general anesthesia. Central venous pressure (CVP) of the right internal jugular vein was measured and routine $\mathrm{HR}, \mathrm{RR}, \mathrm{ECG}, \mathrm{SpO}_{2}$ monitoring was monitored continuously.

After patients were in full oxygen supply and in complete muscle relaxation, insertion of arndt-endobronchial blocker set (AEBS) or 7.0 Fr double-lumens endobronchial tube (DLT) were performed, at the side contralateral to the side for thoracic surgery. Patients were given $1-2 \mu \mathrm{g} /(\mathrm{kg} \bullet \mathrm{min})$ of vecuronium, with intermittent intravenous injection of fentanyl and 1\%-2\% volume discontinuous inhalation of isoflurane anesthesia and were placed in lateral position.

\section{Maintaining of patients}

The correct position of AEBS or DLT was determined with 3-4 mm fiberoptic bronchoscopy (FOB; BF type 3 C40; Olympus, Tokyo, Japan). Patients were maintained with two lung ventilation (TLV) at Vt 10-12 ml/mg, I:E 1:1.5, FIO2 60 and respiratory rate of 12 breaths per min and after catheter reached the thoracic cavity were maintained with OLV at Vt 7-8 ml/ kg, I:E 1:2, FiO2 60 and respiratory rate 15 breaths per min. In order to prevent $\mathrm{V} / \mathrm{Q}$ ratio imbalance due to prolong OLV, suction was performed and was changed to TLV each $30 \mathrm{~min}$. Arterial blood gas sampling were taken and measured.

\section{Observation and data collection}

Airway pressure during OLV, the effective rate for lung collapse and surgical field exposure, and incidence and score of throat pain were measured.

Evaluation of lung collapse and surgical exposure (evaluation criteria refer to Campos et al., [8] method) was performed by a thoracic surgeon blinded to the group assignment. Collapse of the lung was assessed as follows: 1. Excellent: ipsilateral lung completely collapsed, satisfactory exposure of surgical field (all of the lung collapse and the surgical field by the surgeon description); 2. Fair: the basic technical side of the collapsed lung, lungs are still some residual gas, but no lung ventilation, revealed relatively satisfied with the surgical field; 3. Poor: the operated side did not collapse or partial lung collapse, affecting surgical operation.

Throat pain score assessment was performed using a numerical rating scale (NRS) ranging from 1 to 10 recorded by direct questioning of the patients at $6 \mathrm{~h}, 12 \mathrm{~h}$ and $24 \mathrm{~h}$ after surgery. NRS = 0 and NRS $>0$ were considered as painless and painful throat respectively. All the patients were trained on how to answer the NRS.

\section{Statistical Analysis}

For the comparison between the Arndt-endobronchial blocker set (AEBS) and double-lumens endobronchial tube (DLT) in one lung ventilation in thoracic surgery,

i) the primary outcome measure was the comparison between the airway pressure, effective rate for lung collapse and surgical field exposure,

ii) the secondary outcome measure was the comparison between the incidence and severity of throat pain of the patients.

Measurement data were presented as mean \pm standard deviation. Comparison between groups were done using Student's t test, with $\mathrm{P}<0.05$ was considered statistically significant. Analysis was performed using SPSS 17.0 statistical software (SPSS Inc, Chicago, Illinois, USA).

\section{Results and Discussion}

\section{Demographic characteristics}

There was no statistically difference in demographic characteristics between the patients in the AEBS group and DLT group (P > 0.05) (Table 1 and Table 2). 


\section{Type of thoracic surgery}

No significant differences were identified between the AEBS and DLT group with regard to the type of surgery $(\mathrm{P}>0.05)$ (Table 2).

\section{Gas exchange data during OLV}

$\mathrm{PaO} 2$ of patients in the DLT group was significantly higher than the AEBS group $(\mathrm{P}<0.05)$ while $\mathrm{P}(\mathrm{A}-\mathrm{a}) \mathrm{O} 2$ for patients in the DLT group was significantly lower than the AEBS group $(\mathrm{P}<$ 0.05 ) in one lung ventilation (Table 3).

\section{Effective rate for lung collapse and surgical field exposure}

Effective rate for lung collapse and surgical field exposure for the AEBS group was statistically higher than DLT group $(\mathrm{P}<0.05)$ (Table 4).

\section{Incidence of throat pain and throat pain score}

The incidence of throat pain and mean of throat pain score among patients receiving general anesthesia in patients of the AEBS group at $6 \mathrm{~h}, 12 \mathrm{~h}$ and $24 \mathrm{~h}$ after thoracic surgery were significantly lower than the DLT group $(\mathrm{P}<0.05)$ (Figure 1 and
Table 5).

\section{Summary}

Selective intubation was described for the first time in 1932 by Gale and Waters, who aimed to open the thorax and surgically manipulate the lungs [9]. Since then, various alternative methods have been proposed to make this technique safer and facilitate its practice. Complications arise from one lung ventilation include hypoxemia, hemorrhage, hemodynamic instability, bronchial rupture caused by excessive inflation of the balloon on the tip of the double-lumen tube, and alveolar lesions [1].

When there is total collapse, as is the case for the nonventilated lung during one-lung ventilation, reversal of this state is not easily achieved and requires higher pressures to produce alveolar reopening [3]. During one lung ventilation, the dependent lung is ventilated and the nondependent lung is not. As a result, the nondependent lung will be in total collapse, presenting significant reduction in the surface area available for gas exchange. Subsequently, a transpulmonary shunt is created in the nondependent lung. Even in the presence of similar FiO2 and comparable metabolic and hemodynamic conditions, arterial oxygen tension $\left(\mathrm{PaO}_{2}\right)$ is lower than in traditional mechanical ventilation.

Table 1. Demographic Characteristics, Preoperative Pulmonary Function and Preoperative Arterial Blood Gas Values of Patients in the AEBS and DLT Group.

\begin{tabular}{|c|c|c|}
\hline & AEBS group & DLT group \\
\hline Age $(\mathrm{yr})$ & $59 \pm 15$ & $60 \pm 13$ \\
\hline Gender $(\mathrm{M} / \mathrm{F})$ & $16 / 4$ & $16 / 4$ \\
\hline Height $(\mathrm{cm})$ & $167 \pm 9$ & $166 \pm 9$ \\
\hline Weight $(\mathrm{kg})$ & $62 \pm 11$ & $64 \pm 10$ \\
\hline FEV1 (\% predicted) & $79 \pm 13$ & $80 \pm 14$ \\
\hline FRC (\% predicted) & $145 \pm 18$ & $145 \pm 19$ \\
\hline RV $(\%$ predicted) & $152 \pm 20$ & $151 \pm 21$ \\
\hline TLC (\% predicted) & $115 \pm 15$ & $112 \pm 16$ \\
\hline PaCO2 (mm Hg, room air) & $38 \pm 2$ & $39 \pm 2$ \\
\hline PaO2 (mm Hg, room air) & $71 \pm 9$ & $72 \pm 10$ \\
\hline Pre-op BP (mmHg) & $148 \pm 25$ & $143 \pm 22$ \\
\hline Pre-op HR (bpm) & $75 \pm 10$ & $76 \pm 11$ \\
\hline Surgery duration $(\mathrm{h})$ & $3.3 \pm 1.7$ & $3.1 \pm 1.8$ \\
\hline Anesthesia duration $(\mathrm{h})$ & $3.7 \pm 1.9$ & $3.8 \pm 1.8$ \\
\hline
\end{tabular}

Data are presented as mean \pm standard deviation $\mathrm{n}=$ number of patients, FEV1: forced expiratory volume in 1s, FRC: functional residual capacity, RV: residual volume, TLC: total lung capacity.

Table 2. Type of Thoracic Surgery of the 40 Patients.

\begin{tabular}{|c|c|c|}
\hline & AEBS group (n) & DLT group (n) \\
\hline Lobectomy & 12 & 12 \\
\hline Pneumonectomy & 1 & 1 \\
\hline Upper and middle eosophageal resection & 7 & 7 \\
\hline
\end{tabular}

$\mathrm{n}=$ number of patients. 
Table 3. Gas Exchange Data of the 40 Patients Obtained During OLV.

\begin{tabular}{|c|c|c|}
\hline \multirow{2}{*}{ Group } & \multicolumn{2}{|c|}{ OLV } \\
\cline { 2 - 3 } & AEBS & DLT \\
\hline Ppeak $\left(\mathrm{cm} \mathrm{H}_{2} \mathrm{O}\right)$ & $25 \pm 3$ & $22 \pm 4$ \\
\hline Pplateau $\left(\mathrm{cm} \mathrm{H}_{2} \mathrm{O}\right)$ & $17 \pm 2$ & $15 \pm 2$ \\
\hline PEEPi $\left(\mathrm{cm} \mathrm{H}_{2} \mathrm{O}\right)$ & $2.5 \pm 0.3$ & $2.0 \pm 0.5$ \\
\hline $\mathrm{PaCO} 2\left(\mathrm{~mm} \mathrm{Hg}^{2}\right)$ & $38 \pm 6$ & $39 \pm 5$ \\
\hline $\mathrm{PaO} 2\left(\mathrm{~mm} \mathrm{Hg}^{2}\right)$ & $106 \pm 52^{*}$ & $155 \pm 46$ \\
\hline $\mathrm{P}(\mathrm{A}-\mathrm{a}) \mathrm{O} 2(\mathrm{~mm} \mathrm{Hg})$ & $248 \pm 42^{*}$ & $196 \pm 45$ \\
\hline
\end{tabular}

Data are presented as mean \pm standard deviation. OLV: one lung ventilation, Ppeak: peak inspiratory airway pressure, Pplateau: endinspiratory airway pressure, PEEPi: intrinsic positive end-expiratory pressure, $\mathrm{P}(\mathrm{A}-\mathrm{a}) \mathrm{O}_{2}$ : alveolar-arterial oxygen tension difference;

AEBS compared with DLT group $(* \mathrm{P}<0.05)$.

Table 4. Rank of Surgical Exposure.

\begin{tabular}{|c|c|c|}
\hline & AEBS group (n) & DLT group (n) \\
\hline Excellent & 20 & 18 \\
\hline Fair & 0 & 0 \\
\hline Poor & 0 & 2 \\
\hline Effective rate $(\%)$ & 100 & 90 \\
\hline
\end{tabular}

n: number of patients

Table 5. Throat Pain score by NRS among the 40 patients at $6 \mathrm{~h}, 12 \mathrm{~h}$ and $24 \mathrm{~h}$ after Thoracic Surgery.

\begin{tabular}{|c|c|c|c|c|}
\hline \multirow{2}{*}{} & \multicolumn{2}{|c|}{ AEBS group } & \multicolumn{2}{c|}{ DLT group } \\
\cline { 2 - 5 } & Mean & Maximum & Mean & Maximum \\
\hline 6 h after surgery & $4^{*}$ & 5 & 6 & 8 \\
\hline 12 h after surgery & $3^{*}$ & 4 & 5 & 6 \\
\hline 24 h after surgery & $2^{*}$ & 3 & 4 & 5 \\
\hline
\end{tabular}

AEBS compared with DLT group, $(* \mathrm{P}<0.05)$

Figure 1. Incidence of throat pain among the 40 patients at $6 \mathrm{~h}, 12 \mathrm{~h}$ and $24 \mathrm{~h}$ after thoracic surgery; AEBS compared with DLT group $(* \mathbf{P}<0.05)$.

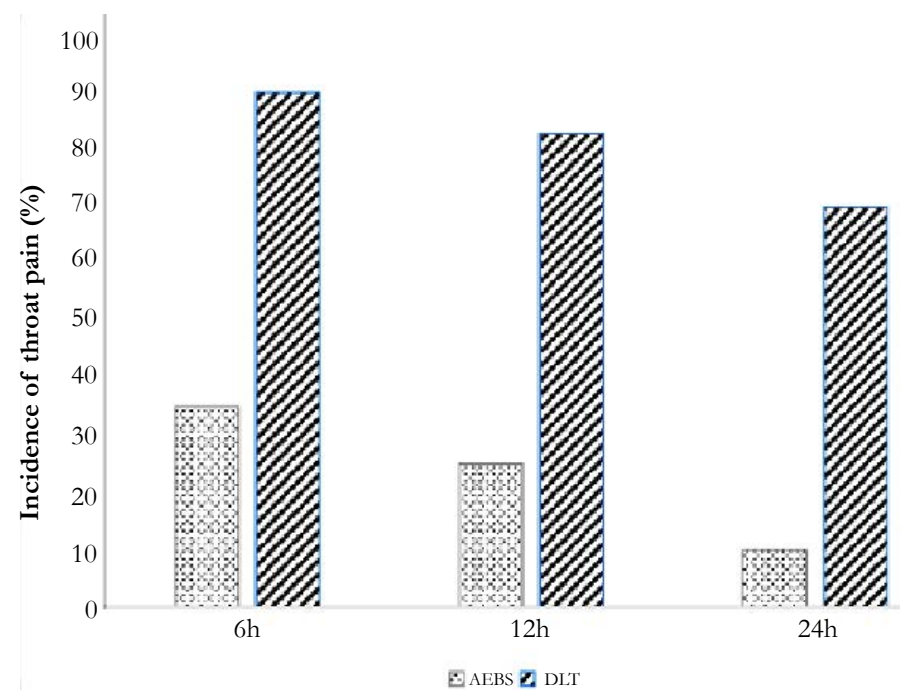


Hypoxemia is a complication that affects $9 \%$ to $27 \%$ of patients undergoing one lung ventilation [3]. Reduces pulmonary blood flow through non-ventilated lung by $40-50 \%$ during OLV resulting in moderation of hypoxia $[10,11]$. Development of hypoxaemia (arterial oxygen saturation $<90 \%$ ) caused by OLV can be explained by three factors, firstly reduction in oxygen stores of the body, poor oxygenation and compromised ventilation, secondly dissociation of oxygen from haemoglobin, thirdly ventilationperfusion relationship [12].

A number of factors may predict the possibility of hypoxia during OLV. However, hypoxia is due to play of multiple factors acting at the same time, influencing each other and lung physiology, per se [13-15].

Lung isolation has been used more frequently in adult and paediatric groups due to increasing incidence of thoracoscopy and video-assisted thoracoscopic surgery in these patients. Indications for lung isolation and OLV include surgical and non-surgical reasons and isolation can be achieved by double-lumen endotracheal tubes (DLT) or bronchial blocker [12].

Lung isolation has been in use for long, but most of the issues is still remain controversial. These include the choice of tube size, method of isolation chosen, unequivocal method of insertion and confirmation of correct placement, optimum $\mathrm{FiO}_{2}$ before and during OLV, the limits of acceptable degree of desaturation, etc [12].

Traditionally anesthesiologists aim to attain a maximum possible of $\mathrm{SpO}_{2}$. In OLV, such margin can be achieved by increasing $\mathrm{FiO}_{2}$ to $100 \%$. However $\mathrm{FiO}_{2} 100 \%$ is liable to cause problems such as hyperoxia, absorption collapse of alveoli, etc. It may be more prudent to tolerate $\mathrm{SpO}_{2}$ of $88 \%$ as the lowest value rather than aiming for $100 \% \mathrm{SpO}_{2}$ with high $\mathrm{FiO}_{2}$ [12].

Execution of one lung ventilation still constitutes a challenge in clinical and surgical practice. Many techniques have been developed to minimize related complications [12]. This selection is often based on the preferences and experiences of the anesthesiologist and surgeon [16] DLTs are the most widely used devices for OLV, however, they have been reported to be associated with potential bronchus injury and sore throat [17].

Sore throat and hoarseness are well-known postoperative complications after tracheal intubation [18]. Zhong and colleagues reported the incidence of sore throat of different bronchial blockers (Coopdech 13\%, Arndt 20\%, and Univent 30\%) [19].

Bronchial blockers has been considered as the best device for patients with difficult airways. There was no cuff damage during intubation and no need to replace a tube if mechanical ventilation is required [13]. Previous study showed that compared with group DLT, Arndt group showed a significantly attenuated hemodynamic response to intubation (blood pressure, $149 \pm 31$ vs. 115 $\pm 16 \mathrm{mmHg}$; heart rate, $86 \pm 15$ vs. $68 \pm 15 \mathrm{bpm})$, less severe injuries to the bronchus (injury score, $1.4 \pm 0.2$ vs. $0.4 \pm 0.1$ ) and vocal cords (injury score, $1.3 \pm 0.2$ vs. $0.6 \pm 0.1$ ), and lower incidences of post-operative sore throat and hoarseness [20].

Bronchial blockers have been used to achieve OLV in patients with restricted mouth opening $[5,21]$ and in paediatric patients for scoliosis surgery [22]. It has an established role in patients with abnormal tracheobronchial tree and requiring thoracic surgery [23]. Study [24] showed that effective OLV could be achieved by using nasotracheal intubation and a bronchial blocker placement which performed with the aid of a fiberoptic bronchoscope in patients with distorted upper and lower airway passages, and it appeared to be the best option for achieving OLV. It is believed that this technique would be useful in clinical situations where placement of double lumen endotracheal tubes is technically impractical or impossible.

Our study was carried out to compare the use of AEBS with DLT in OLV in thoracic surgery. Results showed that $\mathrm{PaO}_{2}$ of patients in the AEBS group was significantly lower than the DLT group during one lung ventilation $(106 \pm 52$ vs. $155 \pm 46)(\mathrm{P}<0.05)$ with $\mathrm{SaPO}_{2}$ range within $97 \%$ - 100\%. Effective rate for lung collapse and surgical field exposure in the AEBS group (20/20 $=100 \%)$ was significantly higher than the DLT group $(18 / 20=$ $90 \%)(\mathrm{P}<0.05)$ while incidence and severity of throat pain in the AEBS group at $6 \mathrm{~h}, 12 \mathrm{~h}$ and $24 \mathrm{~h}$ after thoracic surgery were significantly lower than the DLT group $(\mathrm{P}<0.05)$.

\section{Study limitations}

However, there were some limitations in this study. Further studies could be done to evaluate the comparison at different $\mathrm{FiO}_{2}$ level to obtain an optimum value for intubation.

\section{Conclusion}

AEBS can be used as an effective alternative choice for one lung ventilation with effective lung collapse and surgical field exposure and less incidence and severity of throat pain.

\section{Ethics Approval and Consent to Participate}

This described study was approved by the Ethics Committee of the Cangzhou Central Hospital and in compliance with the Declaration of Helsinki. Informed consent was obtained from all individual participants included in the study.

\section{Acknowledgements}

This study is under the Cangzhou city science and technology research and development projects (Number: 151302063).

\section{References}

[1]. Plummer S, Hartley M, Vaughan RS (1998) Anaesthesia for telescopic procedures in the thorax. Br J Anaesth. 80(2): 223-234.

[2]. Szegedi LL (2001) Pathophysiology of one-lung ventilation. Anesthesiol Clin North America. 19(3):435-453.

[3]. Ferreira HC, Zin WA, Rocco PRM (2004) Physiopathology and clinical management of one-lung ventilation. J Bras Pneumol. 30(5): 566-573.

[4]. Brodsky JB (2009) Lung separation and the difficult airway. Br J Anaesth. 103(1): i66-75. doi: 10.1093/bja/aep262.

[5]. Angie Ho CY, Chen CY, Yang MW, Liu HP (2005) Use of the Arndt wireguided endobronchial blocker via nasal for OLV in patient with anticipated restricted mouth opening for esophagectomy. Eur J Cardiothorac Surg. 28(1): 174-175. doi: 10.1016/j.ejcts.2005.03.013.

[6]. Neustein SM (2009) The use of bronchial blockers for providing one-lung ventilation. J Cardiothorac Vasc Anesth. 23(6): 860-868. doi: 10.1053/j. jvca.2009.05.014. 
[7]. Cohen E (2008) Pro: The new bronchial blockers are preferable to doublelumen tubes for lung isolation. J Cardiothorac Vasc Anesth. 22(6): 920-924. doi: 10.1053/j.jvca.2008.09.002.

[8]. Campos JH, Kernstine KH (2003) A comparison of a left sided Broncho Cath with the torque control blocker univent and the wire guided blocker. Anesth Analg. 96(1): 283-289. doi: 10.1213/00000539-200301000-00056.

[9]. Gale JW, Waters RM (1932) Closed endobronchial anesthesia in thoracic surgery: preliminary report. J Thorac Surg. 1(6):432-437.

[10]. Lohser J (2008) Evidence-based management of one-lung ventilation. Anesthesiol Clin. 26(2): 241-272. doi: 10.1016/j.anclin.2008.01.011.

[11]. Lohser J, Ishikawa S (2011) Physiology of lateral decubitus position, open chest and one lung ventilation. Principles of Practice of Anesthesia for Thoracic Surgery. Springer Science; Business Media, LLC, New York, USA, 7182.

[12]. Purohit A, Bhargava S, Mangal V (2015) Lung isolation, one-lung ventilation and hypoxaemia during lung isolation. Indian J Anaesth. 59(9): 606617. doi: $10.4103 / 0019-5049.165855$.

[13]. Karzai W, Schwarzkopf K (2009) Hypoxemia during one-lung ventilation: Prediction, prevention, and treatment. Anesthesiology. 110(6): 1402-1411. doi: 10.1097/ALN.0b013e31819fb15d.

[14]. Slinger P, Suissa S, Triolet W (1992) Predicting arterial oxygenation during one-lung anaesthesia. Can J Anaesth. 39(10): 1030-1035. doi: 10.1007/ BF03008370.

[15]. Bardoczky GI, Szegedi LL, d'Hollander AA, Moures JM, de Francquen P, et al., (2000) Two-lung and one-lung ventilation in patients with chronic obstructive pulmonary disease: The effects of position and FiO2. Anesth Analg. 90(1): 35-41. doi: 10.1097/00000539-200001000-00008.

[16]. Kosarek L, Busch E, Abbas A, Falterman J, Nossaman BD (2013) Effective use of bronchial blockers in lung isolation surgery: An analysis of 130 cases.
Ochsnern J. 13(3): 389-393.

[17]. Knoll H, Ziegeler S, Schreiber JU, Buchinger H, Bialas P, et al., (2006) Airway injuries after one-lung ventilation: a comparison between double-lumen tube and endobronchial blocker: a randomized, prospective, controlled trial. Anethesiology. 105(3): 471-477.

[18]. Lehmann M, Monte K, Barach P, Kindler CH (2010) Postoperative patient complaints: a prospective interview study of 12276 patients. J Clin Aanesth. 22(1): 13-21. doi: 10.1016/j.jclinane.2009.02.015.

[19]. Zhong T, Wang W, Chen J, Ran L, Story DA (2009) Sore throat or hoarse voice with bronchial blockers or double-lumen tubes for lung isolation: a randomised, prospective trial. Anaesth Intensive Care. 37(3): 441-446.

[20]. Li Q, Li PY, Xu JH, Gu H, Ma Q, et al., (2014) A novel combination of the Arndt endobronchial blocker and the laryngeal mask airway ProSeal ${ }^{\mathrm{TM}}$ provides one-lung ventilation for thoracic surgery. Exp Ther Med. 8(5): 16281632. doi: $10.3892 /$ etm.2014.1966

[21]. Arndt GA, Buchika S, Kranner PW, DeLessio ST (1999) Wire-guided endobronchial blockade in a patient with limited mouth opening. Can J Anaesth. 46(1): 87-89. doi: 10.1007/BF03012521.

[22]. Bird GT, Hall M, Nel L, Davies E, Ross O (2007) Effectiveness of Arndt endobronchial blockers in pediatric scoliosis surgery: A case series. Paediatr Anaesth. 17(3): 289-294. doi: 10.1111/j.1460-9592.2006.02121.x.

[23]. Campos JH (2009) Update on selective lobar blockade during pulmonary resections. Curr Opin Anaesthesiol. 22(1): 18-22. doi: 10.1097/ ACO.0b013e32831a437a.

[24]. Kaza SR, Maddali MM, Albahrani MJ, Vaghari AA (2012) One lung ventilation in a patient with an upper and lower airway abnormality. Indian J Anaesth. 56(6): 567-569. doi: 10.4103/0019-5049.104578. 